\title{
Epilepsy is associated with higher subsequent mortality risk in patients after stroke: a population-based cohort study in Taiwan
}

This article was published in the following Dove Press journal:

Clinical Epidemiology

\author{
Tomor Harnod ${ }^{1,2}$ \\ Cheng-Li Lin ${ }^{3,4}$ \\ Chia-Hung $\mathrm{KaO}^{5-7}$
}

'Department of Neurosurgery, Hualien Tzu Chi General Hospital, Buddhist Tzu Chi Medical Foundation, Hualien, Taiwan; ${ }^{2}$ College of Medicine, Tzu Chi University, Hualien, Taiwan; ${ }^{3}$ Management Office for Health Data, China Medical University Hospital, Taichung, Taiwan; ${ }^{4}$ College of Medicine, China Medical University, Taichung, Taiwan; ${ }^{5}$ Graduate Institute of Biomedical Sciences, College of Medicine, China Medical University, Taichung, Taiwan; ${ }^{6}$ Department of Nuclear Medicine and PET Center, China Medical University Hospital, Taichung, Taiwan;

${ }^{7}$ Department of Bioinformatics and Medical Engineering, Asia University, Taichung, Taiwan
Correspondence: Chia-Hung Kao Graduate Institute of Biomedical Sciences, College of Medicine, China Medical University, No. 2, Yuh-Der Road, Taichung 404, Taiwan

Email dI0040@mail.cmuh.org.tw; dr.kaochiahung@gmail.com

\begin{abstract}
Objective: To use the National Health Insurance Research Database (NHIRD) of Taiwan to determine whether patients with poststroke epilepsy (PSE) in Taiwan have an increased risk of mortality.
\end{abstract}

Methods: We analyzed the data from the NHIRD of patients ( $\geq 40$ years) who had received stroke diagnoses between 2000 and 2012. The patients with stroke were divided into PSE and poststroke non-epilepsy (PSN) cohorts and compared against a sex-, age-, comorbidity-, and index-date-matched cohort from normal population. We calculated adjusted HRs (aHRs) and $95 \%$ CIs of all-cause mortality risk in these cohorts after adjustment for age, sex, and comorbidities.

Results: Among the poststroke patients, $12.14 \%$ constituted the PSE cohort. The cumulative mortality rate was considerably higher in the PSE than in the PSN cohort. The PSE $(\mathrm{aHR}=4.18,95 \% \mathrm{CI}=3.91-4.48)$ and $\mathrm{PSN}(\mathrm{aHR}=1.90,95 \% \mathrm{CI}=1.83-1.98)$ cohorts were associated with higher risks of mortality than the comparison cohort. Furthermore, advanced age ( $\geq 65$ years), male sex, alcohol-related illness, chronic obstructive pulmonary disease, coronary artery disease, diabetes, hypertension, asthma, and cancer would further increase the risk of mortality after a stroke event.

Conclusion: The mortality risk in poststroke patients is approximately two times the likelihood in those with PSE than in those without, and approximately four times higher than that in the normal population. Our findings provide crucial information for clinicians and the government to improve survival after stroke.

Keywords: cohort study, epilepsy, mortality, stroke, National Health Insurance

\section{Introduction}

Worldwide, stroke is a major neurovascular disease that usually occurs suddenly. Patients who survive the acute stage of a stroke usually have various disabilities and comorbidities in their daily lives, thereby resulting in a long-term reduction in the quality of life. To our knowledge, stroke is the most common cause of disability and dependence in the adult population. ${ }^{1-3}$

Epilepsy is also a common neurological disease worldwide; it presents with repetitive seizure episodes and can damage the patient's brain. Epilepsy has a clinical prevalence of $0.5-1 \%$ in the general population. ${ }^{4,5}$ Based on its etiology, poststroke epilepsy (PSE) is currently categorized as a structural epilepsy determined by the brain insult from a stroke. ${ }^{6,7}$ Stroke is known to be one of the leading etiologies of adult epilepsy. ${ }^{4,8}$ Patients who survive a stroke event may experience 
PSE, and the incidence of PSE is approximately $3.1-11.5 \%$ in poststroke patients in developed Western countries. $^{9-11}$ Additionally, researchers reported that patients with epilepsy might have approximately two times higher mortality risk and a shorter life expectancy than those of the general population. ${ }^{12}$ However, the extent of increase in the risk of mortality in patients with stroke and PSE in Taiwan remains unknown, and correlated risk factors could help prevent premature death in these patients. Therefore, additional investigation is required to understand the correlation between mortality risks in poststroke patients with or without PSE to elucidate future treatment strategies for the management of patients after stroke.

We used a nationwide, population-based database to investigate and compare the mortality risks and risk factors between Taiwanese patients with PSE and those patients with stroke without epilepsy (poststroke non-epilepsy, PSN) to elucidate future strategies for poststroke care and reduce the burden of poststroke care. The findings of this study might also aid the future development and implementation of effective treatment strategies in other developing Asian countries.

\section{Methods}

\section{Data source}

We conducted a population-based retrospective cohort study using the Longitudinal Health Insurance Database (LHID) of the National Health Insurance Research Database (NHIRD) of the Taiwan National Health Insurance (NHI) program. The NHI program began in March 1995 and has enrolled more than 99\% of the 23 million residents of Taiwan. ${ }^{13}$ Details regarding the LHID and NHI have been provided in previous studies. ${ }^{14,15}$ This study was approved by the Research Ethics Committee of China Medical University and Hospital in Taiwan (CMUH-104-REC2-115-CR3).

\section{Study population}

Patients aged $\geq 40$ years who had received diagnoses of stroke (International Classification of Diseases, Ninth Revision, Clinical Modification [ICD-9-CM] codes 430-438) between January 1, 2000 and December 31, 2012 were included in the total stroke cohort. Although the International League Against Epilepsy (ILAE) recommendations for epilepsy classification have varied over time, we enrolled PSE and PSN patients by their ICD codes recorded in the NHIRD during the follow-up period that was from on the index date and continued until death, withdrawal from the database, or December 31, 2013. The patients in the total stroke cohort were further divided into two cohorts based on their poststroke epilepsy status: the PSE group included patients who had newly onset epilepsy (ICD-9-CM codes 345) after the stroke event, whereas the PSN group included patients who did not receive an epilepsy diagnosis during the follow-up period. Patients aged $<40$ years or who received epilepsy diagnoses before the stroke event were excluded. The data of patients with missing information of age or sex were excluded. The date of the first PSE diagnosis was defined as the index date, and the index date for the PSN group was a random month and day but with the identical index year to that of the matched patients in the PSE group. For each patient with stroke, two subjects from normal population without a history of stroke or epilepsy were randomly selected from the LHID as comparison cohort; the exclusion criteria used for selecting the total stroke cohort were used for selecting the comparison cohort. The comparison cohort was matched with the stroke cohort using a propensity score; this propensity score was calculated using logistic regression to estimate the probability of the assignment of a stroke status, given the baseline variables: age, sex, comorbidities of alcohol-related illness (ICD-9-CM codes 291, 303, 305.00, 305.01, 305.02, 305.03, 571.0, 571.1, 571.3, 790.3, and V11.3), anxiety disorders (ICD-9-CM 300), mental disorders (ICD-9-CM 290-319), insomnia (ICD-9-CM codes 307.4 and 780.5), depression (ICD-9-CM codes 296.2, 296.3, 296.82, 300.4, and 311), head injury (ICD-9-CM 850-854 and 959.01), chronic obstructive pulmonary disease (COPD) (ICD9-CM codes 491, 492, and 496), coronary artery disease (CAD) (ICD-9-CM code 410-414), diabetes (ICD-9-CM 250), hypertension (ICD-9-CM 401-405), hyperlipidemia (ICD-9-CM 272), cancer (including brain tumor) (ICD9-CM codes 140-208), asthma (ICD-9-CM code 493), and year of index date.

\section{Statistical analysis}

The baseline distribution of demographic characteristics and comorbidities was compared among the stroke cohorts (PSE and PSN) and the comparison cohort. Categorical variables were analyzed using the chi-square test, and the continuous variables of the baseline characteristics of the stroke and comparison cohorts were analyzed using the two sample independent t test. The Kaplan-Meier method was 
used to estimate the cumulative incidence of death among the three cohorts (PSE, PSN, and comparison cohorts), and significance was determined using the log-rank test.

The incidence densities of death were calculated for different risk factors and stratified by age, sex, and comorbidity among the total stroke, PSE, PSN, and comparison cohorts. Univariable and multivariable Cox proportional hazards models were used to estimate the hazard ratios (HRs) and 95\% CIs of mortality associated with the PSE and PSN cohorts and compared with those of the comparison cohort. Variables found to be statistically significant in the univariable model were further included in the multivariable model (including age, sex, comorbidies of alcohol-related illness, anxiety disorders, depression, head injury, COPD, coronary artery disease, diabetes, hypertension, hyperlipidemia, asthma, and cancer). All statistical analyses were performed using SAS statistical software (version 9.4 for Windows; SAS Institute, Inc., Cary, NC, USA). A two-tailed $p$-value of $<0.05$ was considered statistically significant.

\section{Data availability statement}

The dataset used in this study is held by the Taiwan Ministry of Health and Welfare (MOHW). Any researcher interested in accessing this dataset can submit an application form to the MOWH requesting access. Please contact the staff of MOHW (Email: stcarolwu@mohw.gov.tw) for further assistance. Taiwan MOHW address: No. 488, Sec. 6, Zhongxiao E. Road, Nangang District, Taipei City 115, Taiwan. Phone: +886 285906848 .

\section{Results}

In total, we included 13,603 patients with stroke $(87.86 \%$ and $12.14 \%$ constituted the PSN and PSE cohorts, respectively). The comparison cohort consisted of 27,207 subjects from normal population. The baseline characteristics of the three cohorts are presented in Table 1. The PSN and PSE cohorts had a higher (69.7 years) and lower (69.0 years) mean age, respectively, than the comparison cohort (mean age 69.3 years). Among the three cohorts, the majority of

Table I Distribution of age, sex, and comorbidities between stroke and comparison cohorts

\begin{tabular}{|c|c|c|c|c|c|c|c|c|c|}
\hline & \multicolumn{2}{|c|}{$\begin{array}{l}\text { Total stroke } \\
N=13,603\end{array}$} & \multicolumn{2}{|c|}{$\begin{array}{l}\text { Poststroke non-epilepsy } \\
N=1 \text { I,952 }\end{array}$} & \multicolumn{2}{|c|}{$\begin{array}{l}\text { Poststroke epilepsy } \\
N=\text { I,65 I }\end{array}$} & \multicolumn{3}{|c|}{$\begin{array}{l}\text { Comparison cohort } \\
N=27,207\end{array}$} \\
\hline & $\mathbf{n}$ & $\%$ & $\mathbf{n}$ & $\%$ & $\mathbf{n}$ & $\%$ & $\mathbf{n}$ & $\%$ & $P$-value^ \\
\hline Age, years & & & & & & & & & 0.05 \\
\hline $40-64$ & 4,475 & 32.9 & 3,893 & 32.6 & 582 & 35.3 & 9,278 & 34.1 & \\
\hline $65-74$ & 4,064 & 29.9 & 3,612 & 30.2 & 452 & 27.4 & 8,033 & 29.5 & \\
\hline$\geq 75$ & 5,064 & 37.2 & 4,447 & 37.2 & 617 & 37.4 & 9,896 & 36.4 & \\
\hline Mean $(S D)^{\S}$ & 69.7 & 11.8 & 69.8 & 11.7 & 69.0 & 12.6 & 69.3 & 11.5 & $<0.001$ \\
\hline Sex & & & & & & & & & 0.86 \\
\hline Female & 12,052 & 44.3 & 5,353 & 44.8 & 685 & 41.5 & 6,038 & 44.4 & \\
\hline Male & 15,155 & 55.7 & 6,599 & 55.2 & 966 & 58.5 & 7,565 & 55.6 & \\
\hline \multicolumn{10}{|l|}{ Comorbidity } \\
\hline Alcohol-related illness & 633 & 4.65 & 548 & 4.59 & 85 & 5.15 & $|, 35|$ & 4.97 & 0.17 \\
\hline Anxiety disorders & 4,146 & 30.5 & 3,695 & 30.9 & 451 & 27.3 & 8,250 & 30.3 & 0.75 \\
\hline Mental disorders & 7,663 & 56.3 & 6,708 & 56.1 & 955 & 57.8 & 15,152 & 55.7 & 0.22 \\
\hline Insomnia & 9,741 & 71.6 & 8,448 & 70.7 & 1,293 & 78.3 & 19,456 & 71.5 & 0.84 \\
\hline Depression & 1,373 & 10.1 & $\mathrm{I}, 186$ & 9.92 & 187 & 11.4 & 2,797 & 10.3 & 0.56 \\
\hline Head injury & 483 & 3.55 & 376 & 3.15 & 107 & 6.48 & 1,228 & 4.51 & 0.001 \\
\hline COPD & 4,081 & 30.0 & 3,448 & 28.9 & 633 & 38.3 & 7,998 & 29.4 & 0.21 \\
\hline Coronary artery disease & $6,44 I$ & 47.4 & 5,719 & 47.9 & 722 & 43.7 & 12,632 & 46.4 & 0.08 \\
\hline Diabetes & 3,545 & 26.1 & 3,127 & 26.2 & 418 & 25.3 & 6,875 & 25.3 & 0.08 \\
\hline Hypertension & 11,953 & 87.9 & 10,483 & 87.7 & 1470 & 89.0 & 23,845 & 87.6 & 0.51 \\
\hline Hyperlipidemia & 6,024 & 44.3 & 5,413 & 45.3 & 611 & 37.0 & 11,902 & 43.8 & 0.30 \\
\hline Asthma & 1,994 & 14.7 & 1,712 & 14.3 & 282 & 17.1 & 4,098 & 15.1 & 0.28 \\
\hline Cancer (including brain tumor) & 775 & 5.70 & 682 & 5.71 & 93 & 5.63 & 1,589 & 5.84 & 0.56 \\
\hline
\end{tabular}

Notes: Chi-square test; ${ }^{\S}$-test; ${ }^{\wedge}$ total stroke vs comparison cohort. 
patients were male $(55.2 \%$ in the PSN cohort, $58.5 \%$ in the PSE cohort, and 55.6\% in the comparison cohort) (Table 1).

The median and range of follow-up in PSN cohort, PSE cohort, and comparison cohort were 4.21 (range $=0.003-14.0), 3.05$ (range $=0.003-14.0$ ), and 5.22 (range $=0.003-14.0$ ), respectively. As shown in Figure 1, the cumulative incidence of mortality estimated using the Kaplan-Meier method revealed significant differences among the three cohorts during the follow-up period $(p<0.001)$. The cumulative incidence mortality rate was considerably higher in the PSE cohort than that in the PSN and comparison cohorts (Figure 1). Compared with the comparison cohort, the total stroke cohort (adjusted $\mathrm{HR}=2.12$, 95\% $\mathrm{CI}=2.04-2.20$ ), PSE cohort (adjusted $\mathrm{HR}=4.18, \quad 95 \% \quad \mathrm{CI}=3.91-4.48) \quad$ and $\mathrm{PSN}$ cohort (adjusted $\mathrm{HR}=1.90$, 95\% $\mathrm{CI}=1.83-1.98$ ) were associated with significantly higher risks of mortality. Among all study cohorts, the risk of mortality was higher in the patients aged $\geq 75$ years (adjusted $\mathrm{HR}=5.07$, 95\% $\mathrm{CI}=4.78-5.38$ ) and those aged 65-74 years (adjusted $\mathrm{HR}=2.29$, 95\% $\mathrm{CI}=2.15-2.43$ ) than in those aged 40-64 years. The risk of mortality was higher in male patients than in female patients. Among the comorbidities, alcoholrelated illness (adjusted $\mathrm{HR}=1.30,95 \% \mathrm{CI}=1.17-1.45$ ), COPD (adjusted $\mathrm{HR}=1.28$, 95\% $\mathrm{CI}=1.23-1.33$ ), $\mathrm{CAD}$ (adjusted $\mathrm{HR}=1.10, \quad 95 \% \quad \mathrm{CI}=1.05-1.14$ ), diabetes (adjusted $\mathrm{HR}=1.64,95 \% \mathrm{CI}=1.57-1.71$ ), hypertension (adjusted $\mathrm{HR}=1.10,95 \% \mathrm{CI}=1.03-1.17$ ), asthma (adjusted

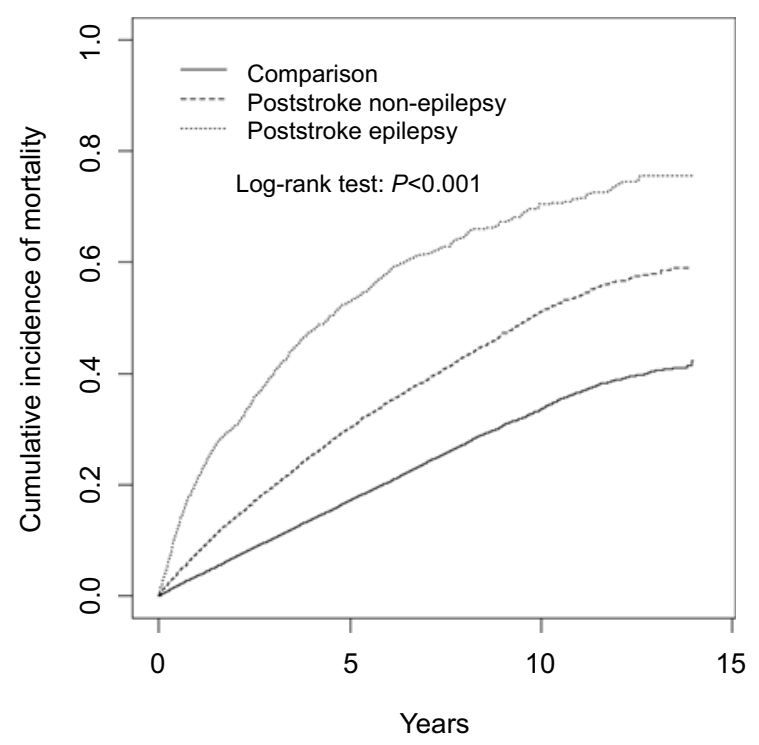

Figure I Comparison of cumulative incidence of mortality among the patients with poststroke epilepsy, patients with stroke without epilepsy, and comparisons from normal population.
$\mathrm{HR}=1.11,95 \% \mathrm{CI}=1.05-1.16$ ), and cancer (including brain tumor) (adjusted $\mathrm{HR}=1.69$, 95\% $\mathrm{CI}=1.58-1.81$ ) were risk factors associated with increased mortality. The other comorbidities were reciprocal factors for low mortality risk (Table 2).

Table 3 shows the comparison of mortality incidence and HRs measured using the Cox model among the poststroke cohorts (PSE and PSN) and comparison cohort after stratification by age, sex, and comorbidities. The adjusted HRs of mortality in the PSE and PSN cohorts were all significantly higher than those of the comparison cohort in all age groups, both sexes, and irrespective of the presence of comorbidities (Table 3 ).

When we used the PSN cohort as the reference group and analyzed the age-specific mortality risk after stratification by age, the risks of mortality were significantly higher in the PSE cohort than in the PSN cohort among all the age groups. Similarly, the sex-specific mortality risk was significantly higher for both the sexes in the PSE cohort than in the PSN cohort. The mortality risk analyzed after stratification by comorbidities in the PSE cohort showed significantly high risks in patients in both strata (patients without comorbidities, adjusted $\mathrm{HR}=8.57, \quad 95 \%$ $\mathrm{CI}=3.49-21.1$; patients with any one of comorbidities, adjusted $\mathrm{HR}=2.21,95 \% \mathrm{CI}=2.06-2.37$ ) (Table 4).

\section{Discussion}

The subsequent all-cause mortality risk in poststroke patients in Taiwan was approximately two times the likelihood in patients with PSE than those without (4.18 and 1.90, respectively, in adjusted HRs) and approximately four times higher than that in the normal population. Comparing to a similar study in a Western country in that the patients with remote structural epilepsy had 3.7 times of mortality rate, ${ }^{12}$ our study revealed a considerably higher mortality risk in the Taiwanese patients with PSE. Additionally, although epilepsy could not be isolated from other factors in the study as in other like this, we still noticed that advanced age ( $\geq 65$ years), male sex, alcohol-related illness, COPD, CAD, diabetes, hypertension, asthma, and cancer would further increase the mortality risk of patients. High mortality risks in patients with PSE were observed in both sexes, all age groups ( $>40$ years), and irrespective of the presence of various comorbidities. Considering the sex differences in mortality risk, we learned that women have been reported to be more easily convinced than men to use additional medical services and spend money on health care. ${ }^{16,17}$ 
Table 2 Incidence and HR for mortality and associated risk factors

\begin{tabular}{|c|c|c|c|c|c|}
\hline & Event (N) & Person-years & Rate & Crude HR (95\% Cl) & Adjusted HR $(95 \% \mathrm{CI})^{*}$ \\
\hline \multicolumn{6}{|l|}{ Stroke } \\
\hline Comparison cohort & 6,120 & 156,160 & 39.2 & 1.00 & 1.00 \\
\hline Poststroke non-epilepsy & 4,199 & 58,806 & 71.4 & $1.82(1.75,1.89)$ & $1.90(1.83,1.98)$ \\
\hline Poststroke epilepsy & 965 & 6,722 & 143.6 & $3.65(3.41,3.91)$ & $4.18(3.91,4.48)$ \\
\hline Total stroke & 5,164 & 65,528 & 78.8 & $2.01(1.93,2.08)$ & $2.12(2.04,2.20)$ \\
\hline \multicolumn{6}{|l|}{ Age, year } \\
\hline $40-64$ & $\mathrm{I}, 534$ & 84,946 & 18.1 & 1.00 & 1.00 \\
\hline $65-74$ & 3,065 & 69,777 & 43.9 & $2.44(2.29,3.59)$ & $2.29(2.15,2.43)$ \\
\hline$\geq 75$ & 6,685 & 66,965 & 99.8 & $5.62(5.31,5.94)$ & $5.07(4.78,5.38)$ \\
\hline \multicolumn{6}{|l|}{ Sex } \\
\hline Female & 4,658 & 99,949 & 46.6 & 1.00 & 1.00 \\
\hline Male & 6,626 & 121,740 & 54.4 & $1.17(1.13,1.21)$ & $1.18(1.13,1.23)$ \\
\hline \multicolumn{6}{|l|}{ Comorbidity } \\
\hline \multicolumn{6}{|l|}{ Alcohol-related illness } \\
\hline No & 10,928 & 212,580 & 51.4 & 1.00 & 1.00 \\
\hline Yes & 356 & 9,109 & 39.1 & $0.76(0.68,00.84)$ & $1.30(1.17,1.45)$ \\
\hline \multicolumn{6}{|l|}{ Anxiety disorders } \\
\hline No & 8,564 & 155,907 & 54.9 & 1.00 & 1.00 \\
\hline Yes & 2,720 & 65,782 & 41.4 & $0.75(0.72,0.78)$ & $0.75(0.71,0.79)$ \\
\hline \multicolumn{6}{|l|}{ Mental disorders } \\
\hline No & 4,968 & 99,244 & 50.1 & 1.00 & 1.00 \\
\hline Yes & 6,316 & 122,445 & 51.6 & $1.03(0.99,1.07)$ & \\
\hline \multicolumn{6}{|l|}{ Insomnia } \\
\hline No & 3,475 & 69,595 & 49.9 & 1.00 & 1.00 \\
\hline Yes & 7,809 & 152,093 & 51.3 & $1.02(0.98,1.06)$ & \\
\hline \multicolumn{6}{|l|}{ Depression } \\
\hline No & 10,383 & $|99,90|$ & 51.9 & 1.00 & 1.00 \\
\hline Yes & 901 & 21,788 & 41.4 & $0.79(0.74,0.85)$ & $1.06(0.99,1.15)$ \\
\hline \multicolumn{6}{|l|}{ Head injury } \\
\hline No & 10,982 & 212,362 & 51.7 & 1.00 & 1.00 \\
\hline Yes & 302 & 9,327 & 32.4 & $0.63(0.56,0.70)$ & $0.91(0.81,1.02)$ \\
\hline \multicolumn{6}{|l|}{ COPD } \\
\hline No & 6,722 & 161,528 & 41.6 & 1.00 & 1.00 \\
\hline Yes & 4,562 & 60,160 & 75.8 & $1.82(1.75,1.89)$ & $1.28(1.23,1.33)$ \\
\hline \multicolumn{6}{|l|}{ Coronary artery disease } \\
\hline No & 5,303 & 120,403 & 44.0 & 1.00 & 1.00 \\
\hline Yes & 5,981 & 101,285 & 59.1 & $1.34(1.29,1.39)$ & $1.10(1.05,1.14)$ \\
\hline
\end{tabular}




\begin{tabular}{|c|c|c|c|c|c|}
\hline & Event (N) & Person-years & Rate & Crude HR (95\% CI) & Adjusted HR (95\% CI)* \\
\hline \multicolumn{6}{|c|}{ Diabetes } \\
\hline No & 7,767 & 167,602 & 46.3 & 1.00 & 1.00 \\
\hline Yes & 3,517 & 54,087 & 65.0 & $1.40(1.35,1.46)$ & $1.64(1.57,1.71)$ \\
\hline \multicolumn{6}{|c|}{ Hypertension } \\
\hline No & 1,068 & 27,513 & 38.8 & 1.00 & 1.00 \\
\hline Yes & 10,216 & 194,176 & 52.6 & $1.35(1.27,1.44)$ & $1.10(1.03,1.17)$ \\
\hline \multicolumn{6}{|c|}{ Hyperlipidemia } \\
\hline No & 7,622 & 126,993 & 60.0 & 1.00 & 1.00 \\
\hline Yes & 3,662 & 94,696 & 38.7 & $0.64(0.62,0.67)$ & $0.64(0.62,0.67)$ \\
\hline \multicolumn{6}{|c|}{ Asthma } \\
\hline No & 9,232 & $|9|, 80 \mid$ & 48.1 & 1.00 & 1.00 \\
\hline Yes & 2,052 & 29,887 & 68.7 & $1.42(1.36,1.49)$ & $1.11(1.05,1.16)$ \\
\hline \multicolumn{6}{|c|}{ Cancer (including brain tumor) } \\
\hline No & 10,333 & 212,448 & 48.6 & 1.00 & 1.00 \\
\hline Yes & 951 & 9,240 & 102.9 & $2.11(1.97,2.25)$ & $1.69(1.58,1.81)$ \\
\hline
\end{tabular}

Notes: Rate, per 1,000 person-years; *variables found to be statistically significant in the univariable model were further included in the multivariable model.

This observation may explain the lower mortality risk in women than in men after a stroke event. Therefore, we suggested PSE as a contributory factor for increasing mortality in poststroke patients in Taiwan even when considered that there would be overlapping comorbidities in some cases or there would be concomitantly more PSE and higher mortality in some severe handicapped poststroke cases. All these conditions might reasonably lead to a higher risk of subsequent mortality in poststroke patients.

This cohort study revealed that $12.14 \%$ of poststroke patients would develop epilepsy and the incidence of PSE in Taiwan was higher than those (3.1-11.5\%) reported in developed Western countries. ${ }^{9-11}$ We consider that the different local findings in incidence and long-term mortality rate in patients with PSE are contributed from that we have progressively reduced acute mortality rate of stroke for 2 decades. ${ }^{18}$ Stroke is currently the fourth leading mortality cause in Taiwan. The more survival patients after stroke events might cause more handicapped and comorbid ones in the society, and that could result more PSE patients and higher averaged long-term mortality rate in them. Furthermore, a recent study in the United States has revealed an interesting tendency of higher epilepsy-related death in Black and Asian population than in non-Hispanic White ones. ${ }^{19}$ All of these may result a higher PSE incidence and its higher mortality rate in poststroke patients in Taiwan.

Epileptogenesis involves molecular and cellular alterations after a brain insult. It increases brain excitability and eventually enables the brain tissue to generate spontaneous recurrent seizures. Because we currently cannot reliably identify a patient with developing epileptogenesis and reverse it after a brain insult, ${ }^{20,21}$ understanding the incidence, outcome risk, and treating correlated risk factors for PSE are practically beneficial for daily clinical practices other than to prevent epileptogenesis. Thus, according to our results, once a patient experiences a stroke event in Taiwan, PSE is considerably expected to play a more critical role than was previously thought in long-term care, and it affects long-term care more prominently than other factors do. PSE directly increases the care burden of families, societies, and the government. Additional studies in different countries are required to confirm whether this result is globally applicable.

In this study, we intentionally enrolled patients with both first-time and recurrent stroke events to estimate the correlation of subsequent PSE and poststroke inpatient all-cause mortality; we excluded cases of mortality occurring outside hospitals in this study. The NHI program, which is a universal mandatory insurance 
Table 3 Comparison of incidence and HR for mortality stratified by age, sex, and comorbidity between poststroke and comparison cohorts

\begin{tabular}{|c|c|c|c|c|c|c|c|c|c|c|c|}
\hline & \multirow{2}{*}{\multicolumn{2}{|c|}{$\begin{array}{l}\text { Comparison } \\
\text { cohort } \\
\mathrm{N}=\mathbf{2 7 , 2 0 7}\end{array}$}} & \multicolumn{9}{|c|}{ Poststroke } \\
\hline & & & \multicolumn{3}{|c|}{ Total stroke $(\mathrm{N}=\mid 3,603)$} & \multicolumn{3}{|c|}{$\begin{array}{l}\text { Poststroke non-epilepsy } \\
(\mathrm{N}=\mid \mathrm{I}, 952)\end{array}$} & \multicolumn{3}{|c|}{$\begin{array}{l}\text { Poststroke epilepsy } \\
(\mathrm{N}=\mathrm{I}, 65 \mathrm{I})\end{array}$} \\
\hline & $\begin{array}{l}\text { Event } \\
\text { (N) }\end{array}$ & Rate & $\begin{array}{l}\text { Event } \\
(\mathbf{N})\end{array}$ & Rate & $\begin{array}{l}\text { Adjusted } \\
\text { HR (95\% } \\
\text { CI) }\end{array}$ & $\begin{array}{l}\text { Event } \\
\text { (N) }\end{array}$ & Rate & $\begin{array}{l}\text { Adjusted } \\
\text { HR }(95 \% \\
\mathrm{Cl})^{*}\end{array}$ & $\begin{array}{l}\text { Event } \\
\text { (N) }\end{array}$ & Rate & $\begin{array}{l}\text { Adjusted } \\
\text { HR (95\% } \\
\text { CI) }\end{array}$ \\
\hline \multicolumn{12}{|l|}{ Age, years } \\
\hline $40-64$ & 717 & 12.2 & 817 & 31.2 & $\begin{array}{l}2.72(2.46 \\
3.01)\end{array}$ & 604 & 26.2 & $\begin{array}{l}2.32(2.08 \\
2.58)\end{array}$ & 213 & 66.4 & $\begin{array}{l}5.38(4.6 \mathrm{I}, \\
6.28)\end{array}$ \\
\hline $65-74$ & I,526 & 31.1 & I,539 & 74.6 & $\begin{array}{l}2.50(2.33 \\
2.69)\end{array}$ & I,257 & 66.7 & $\begin{array}{l}2.24(2.08 \\
2.4 I)\end{array}$ & 282 & 157.4 & $\begin{array}{l}5.28(4.65 \\
6.00)\end{array}$ \\
\hline $\begin{array}{c}\geq 75 \\
\quad P \text { for } \\
\text { interaction }\end{array}$ & 3,877 & 80.3 & 2,808 & 150.4 & $\begin{array}{l}1.94(1.85 \\
2.04) \\
<0.001\end{array}$ & 2,338 & 138.0 & $\begin{array}{l}1.79(1.70, \\
1.88) \\
<0.001\end{array}$ & 470 & 272.6 & $\begin{array}{l}3.38(3.07 \\
3.72)\end{array}$ \\
\hline \multicolumn{12}{|l|}{ Sex } \\
\hline Female & 2,515 & 35.8 & 2,143 & 72.2 & $\begin{array}{l}2.12(2.00 \\
2.24)\end{array}$ & $|, 75|$ & 65.3 & $\begin{array}{l}1.91(1.80 \\
2.04)\end{array}$ & 392 & 137.8 & $\begin{array}{l}3.99(3.59, \\
4.45)\end{array}$ \\
\hline $\begin{array}{c}\text { Male } \\
P \text { for } \\
\text { interaction }\end{array}$ & 3,605 & 42.0 & 3,021 & 84.3 & $\begin{array}{l}2.12(2.02 \\
2.23) \\
0.90\end{array}$ & 2,448 & 76.6 & $\begin{array}{l}1.90(1.80, \\
2.00) \\
0.40\end{array}$ & 573 & 147.8 & $\begin{array}{l}4.28(3.91, \\
4.67)\end{array}$ \\
\hline \multicolumn{12}{|c|}{ Comorbidity } \\
\hline None & 70 & 29.2 & 49 & 47.7 & $\begin{array}{l}1.88(1.31 \\
2.72)\end{array}$ & 43 & 43.0 & $\begin{array}{l}1.69(1.16 \\
2.47)\end{array}$ & 6 & 226.4 & $\begin{array}{l}16.1(6.79 \\
38.4)\end{array}$ \\
\hline $\begin{array}{l}\text { With any } \\
\text { one } \\
\quad P \text { for } \\
\text { interaction }\end{array}$ & 6,050 & 39.4 & 5,115 & 79.3 & $\begin{array}{l}2.08(2.00, \\
2.16) \\
0.26\end{array}$ & 4,156 & 71.9 & $\begin{array}{l}1.86(1.79, \\
1.94) \\
0.84\end{array}$ & 959 & 143.2 & $\begin{array}{l}4.20(3.92, \\
4.49)\end{array}$ \\
\hline
\end{tabular}

Notes: Rate, per I,000 person-years; *variables found to be statistically significant in the univariable model were further included in the multivariable model.

program, has been covering more than $99 \%$ of Taiwan's population for more than 20 years. The program guarantees residents of Taiwan equal access to medical service regardless of their socioeconomic status, background, and critical illness status. ${ }^{13,22}$ Taiwan's universal health care system has resulted in relatively few disparities in access to inpatient services and ultimate outcomes between different hospitals and across different areas in Taiwan. $^{23,24}$ Therefore, the proportion of patients with stroke or PSE dying outside hospitals is low. However, the possibility of underestimation bias in the results should be considered.

Because this study included a nationwide, populationbased sample with a relatively low risk of recall or selection bias, our findings are valuable for the clinicians and the NHI of Taiwan. Moreover, our results can be used as a reference for other developing Asian countries with a heritage similar to that of Taiwan. However, this study has several limitations. First, we could not directly contact the patients because their identities are anonymized in the NHIRD. Therefore, the study design did not include details regarding the type or severity score of their stroke events, the burden or severity of their epilepsy events, or how PSE was treated in the cohort. Second, although the NHI program performs thorough quarterly reviews to ensure that the files are accurate and that false claims are heavily penalized, rare occurrences of miscoding may have nevertheless 
Table 4 Comparison of incidence and hazard ratio for mortality stratified by age, sex, and comorbidities between poststroke patients with and without epilepsy

\begin{tabular}{|c|c|c|}
\hline & $\begin{array}{l}\text { Poststroke non- } \\
\text { epilepsy } \\
\mathrm{N}=\text { I I,952 }\end{array}$ & $\begin{array}{l}\text { Poststroke epi- } \\
\text { lepsy } \\
N=\mid, 65 \text { I }\end{array}$ \\
\hline & $\begin{array}{l}\text { Adjusted } H^{*} \\
(95 \% \mathrm{Cl})\end{array}$ & $\begin{array}{l}\text { Adjusted HR* } \\
(95 \% \mathrm{Cl})\end{array}$ \\
\hline All & 1.00 & $2.13(1.98,2.29)$ \\
\hline \multicolumn{3}{|l|}{ Age, years } \\
\hline $40-64$ & 1.00 & $2.26(1.93,2.66)$ \\
\hline $65-74$ & 1.00 & $2.33(2.04,2.65)$ \\
\hline$\geq 75$ & 1.00 & $1.86(1.68,2.06)$ \\
\hline \multicolumn{3}{|l|}{ Sex } \\
\hline Female & 1.00 & $2.06(I .85,2.3 I)$ \\
\hline Male & 1.00 & $2.16(1.97,2.36)$ \\
\hline \multicolumn{3}{|l|}{ Comorbidity } \\
\hline None & 1.00 & $8.57(3.49,21.1)$ \\
\hline With any one & 1.00 & $2.21(2.06,2.37)$ \\
\hline
\end{tabular}

Notes: *Variables found to be statistically significant in the univariable model were further included in the multivariable model.

occurred in the NHIRD. Additionally, we could not ascertain whether poststroke mortality was directly caused by the stroke event itself, PSE, or other poststroke comorbidities. Finally, although our study design included adequate control of numerous confounding factors, unmeasured or unknown confounders may have generated a bias. However, after considering the aforementioned limitations, our results indicated that the sample size was sufficient to statistically demonstrate the high subsequent mortality risk in patients with PSE.

\section{Conclusion}

The mortality risk in patients with stroke is approximately two times the likelihood in those with PSE than in those without, and approximately four times higher than that in the normal population. Our findings provide vital information for clinicians and the government to improve the long-term survival of patients with stroke in the future.

\section{Data sharing statement}

The dataset used in this study is held by the Taiwan Ministry of Health and Welfare (MOHW). Any researcher interested in accessing this dataset can submit an application form to the MOWH requesting access. Please contact the staff of MOHW (Email: stcarolwu@mohw.gov.tw) for further assistance. Taiwan MOHW address: No.488, Sec. 6, Zhongxiao E. Road, Nangang Dist.rict, Taipei City 115, Taiwan. Phone: +886 2-8590-6848.886

\section{Acknowledgments}

This work was supported by grants from the Ministry of Health and Welfare, Taiwan (MOHW107-TDU-B-212123004), China Medical University Hospital (CMU106ASIA-12, DMR-107-192), Academia Sinica Stroke Biosignature Project (BM10701010021), MOST Clinical Trial Consortium for Stroke, Taiwan (MOST 106-2321-B039-005-), Tseng-Lien Lin Foundation, Taiwan, and Katsuzo and Kiyo Aoshima Memorial Funds, Japan. The funders had no role in study design, data collection and analysis, decision to publish, or preparation of the manuscript. No additional external funding was received for this study.

\section{Author contributions}

All authors contributed to data analysis, drafting and revising the article, gave final approval of the version to be published, and agree to be accountable for all aspects of the work.

\section{Disclosure}

The authors report no conflicts of interest in this work.

\section{References}

1. Howard-Wilsher S, Irvine L, Fan H, et al. Systematic overview of economic evaluations of health-related rehabilitation. Disabil Health J. 2016;9:11-25. doi:10.1016/j.dhjo.2015.08.009

2. Di Rienzo F, Collet C, Hoyek N, Guillot A. Impact of neurologic deficits on motor imagery: a systematic review of clinical evaluations. Neuropsychol Rev. 2014;24:116-147. doi:10.1007/ s11065-014-9257-6

3. Ma VY, Chan L, Carruthers KJ. Incidence, prevalence, costs, and impact on disability of common conditions requiring rehabilitation in the United States: stroke, spinal cord injury, traumatic brain injury, multiple sclerosis, osteoarthritis, rheumatoid arthritis, limb loss, and back pain. Arch Phys Med Rehabil. 2014;95:986-995.

4. Hesdorffer DC, Logroscino G, Benn EK, Katri N, Cascino G, Hauser WA. Estimating risk for developing epilepsy: a population-based study in Rochester, Minnesota. Neurology. 2011;76:23-27. doi:10.1212/WNL.0b013e318204a36a

5. Baldin E, Hauser WA, Buchhalter JR, Hesdorffer DC, Ottman R. Utility of EEG activation procedures in epilepsy: a population-based study. J Clin Neurophsysiol. 2017;34:512-519. doi:10.1097/ WNP.0000000000000371

6. Fisher RS, Acevedo C, Arzimanoglou A, et al. ILAE official report: a practical clinical definition of epilepsy. Epilepsia. 2014;55: 475-482. doi:10.1111/epi.12550

7. Scheffer IE, Berkovic S, Capovilla G, et al. ILAE classification of the epilepsies: position paper of the ILAE Commission for Classification and Terminology. Epilepsia. 2017;58:512-521. doi:10.1111/epi.13709 
8. Annegers JF, Rocca WA, Hauser WA. Causes of epilepsy: contributions of the Rochester epidemiology project. Mayo Clin Proc. 1996;71:570-575. doi:10.4065/71.6.570

9. Lossius MI, Rønning OM, Slapø GD, Mowinckel P, Gjerstad L. Posstroke epilepsy: occurrence and predictors- a long-term prospective controlled study (Akershus Stroke Study). Epilepsia. 2005;46:1246-1251. doi:10.1111/j.1528-1167.2005.57904.x

10. Jungehulsing GJ, Heuschmann PU, Holtkamp M, Schwab S, Kolominsky-Rabas PL. Incidence and predictors of post-stroke epilepsy. Acta Neurol Scad. 2013;127:427-430. doi:10.1111/ ane. 12070

11. Burn J, Dennis M, Bamford J, Sandercock P, Wade D, Warlow C. Epileptic seizures after a first stroke: the Oxfordshire Community Stroke Project. BMJ. 1997;315:1582-1587. doi:10.1136/ bmj.315.7122.1582

12. Lhatoo SD, Johnson AL, Goodridge DM, MacDonald BK, Sander JW, Shorvon SD. Mortality in epilepsy in the first 11 to 14 years after diagnosis: multivariate analysis of a long-term, prospective, population-based cohort. Ann Neurol. 2001;49:336-344. doi:10.1002/ana.70

13. Database NHIR. Taiwan [cited 2017]. Available from: http://nhird. nhri.org.tw/en/index.html.Accessed March 8, 2019.

14. Lin SY, Lin CL, Lin CC, Wang IK, Hsu WH, Kao CH. Risk of acute coronary syndrome and peripheral arterial disease in chronic liver disease and cirrhosis: a nationwide population-based study. Atherosclerosis. 2018;270:154-159. doi:10.1016/j.atherosclerosis. 2018.01 .047

15. Li HM, Sung FC, Li SC, et al. The effect of antibiotic prophylaxis for acute pelvic inflammatory disease after hysterosalpingography: a retrospective cohort study. Curr Med Res Opin. 2018;10:1-6.

16. Kaur S, Stechuchak KM, Coffman CJ, Allen KD, Bastian LA. Gender differences in health care utilization among veterans with chronic pain. J Gen Intern Med. 2007;22:228-233. doi:10.1007/ s11606-006-0069-0
17. Owens GM. Gender differences in health care expenditures, resource utilization, and quality of care. J Manag Care Pharm. 2008;14 Supp 1:2-6.

18. Ministry of Health and Welfare. Taiwan. https://www.mohw.gov.tw/ lp-3267-2.html.Accessed March 8, 2019.

19. Greenlund SF, Croft JB, Kobau R. Epilepsy by the numbers: epilepsy deaths by age, race/ ethnicity,and gender in the United States significantly increased from 2005 to 2014. Epilepsy Behav. 2017;69:28-30. doi:10.1016/j.yebeh.2017.01.016

20. Lusardi TA, Akula KK, Coffman SQ, Ruskin DN, Masino SA, Boison D. Ketogenic diet prevents epileptogenesis and disease progression in adult mice and rats. Neuropharmacology. 2015;99:500-509. doi:10.1016/j.neuropharm.2015.07.008

21. Pitkänen A, Kharatishvili I, Karhunen H, et al. Epileptogenesis in experimental models. Epilepsia. 2007;48 Suppl 2:13-20. doi:10.1111/j.1528-1167.2007.01063.x

22. Lee YH, Ang TFA, Chiang TC, Kaplan WA. Growing concerns and controversies to Taiwan National Health Insurance- what are the lessons from mainland China, South Korea and Singapore? Int J Health Plann Manage. 2018;33:e357-e366. doi:10.1002/ hpm. 2387

23. Huang N, Yip W, Chang HJ, Chou YJ. Trends in rural and urban differentials in incidence rates for ruptured appendicitis under the National Health Insurance in Taiwan. Public Health. 2006;120:1055-1063. doi:10.1016/j.puhe.2006.06.011

24. Shu CC, Lin JW, Lin YF, Hsu NC, Ko WJ. Evaluating the performance of a hospitalist system in Taiwan: a pioneer study for nationwide health insurance in Asia. J Hosp Med. 2011;6:378-382. doi:10.1002/jhm.896
Clinical Epidemiology

\section{Publish your work in this journal}

Clinical Epidemiology is an international, peer-reviewed, open access, online journal focusing on disease and drug epidemiology, identification of risk factors and screening procedures to develop optimal preventative initiatives and programs. Specific topics include: diagnosis, prognosis, treatment, screening, prevention, risk factor modification,

\section{Dovepress}

systematic reviews, risk \& safety of medical interventions, epidemiology \& biostatistical methods, and evaluation of guidelines, translational medicine, health policies \& economic evaluations. The manuscript management system is completely online and includes a very quick and fair peer-review system, which is all easy to use. 